\title{
Helping At The Edges Of Life: Perspectives Of A Psychedelic Therapist
}

\author{
Richard Yensen, Ph.D. \\ Institute for Human Development
}

\begin{abstract}
A case history is presented of a 70 year old man treated with psychedelic psychotherapy for depression, anxiety, and pain associated with terminal cancer. Interpersonal and intrapersonal aspects of treatment following a single $90 \mathrm{mg}$ dose of dipropyltryptamine (DPT) are described. Comparisons are made between transpersonal, mystical, and religious elements in psychedelic drug experiences and near-death experiences.
\end{abstract}

I have been involved, over the last 15 years, as a researcher and psychotherapist in the difficult and controversial field of legitimate, government-regulated, psychedelic drug research. One of the most interesting aspects of this work has been our research group's investigation of psychedelic psychotherapy as a way to assist cancer patients in overcoming depression, anxiety, and pain (Richards, Rhead, Di Leo, Yensen, \& Kurland, 1977; Kurland, 1985). In our work with psychedelics and terminal cancer patients the goal is to provide the individual facing death with an opportunity to have a powerful confrontation

This paper is based on a study in which the author participated as a research psychotherapist at the Maryland Psychiatric Research Center. The author gives special thanks to the late Dr. T. Glyne Williams for his supervision, and to Dr. Albert A. Kurland for his administrative support of this work, and also thanks Friends of Medical Science Research, the Maryland Psychiatric Research Center, the Maryland Department of Health and Mental Hygiene, and the Mary Reynolds Babcock Foundation for the opportunity to carry out this work.

Dr. Yensen is currently Director of the Institute for Human Development, and Instructor in Psychology, Harvard Medical School. Requests for reprints should be addressed to Dr. Yensen at the Institute for Human Development, 2403 Talbot Road, Baltimore, MD 21216. 
with the existential issues of dying in a supportive, psychotherapeutic setting. When psychedelic drugs are administered in this way, they produce an experience of altered consciousness that frequently includes a life review, confrontation with death, rebirth, and awareness of the ultimate ground of being, or God.

Over the years I have come to see that the experiences of my patients in psychedelic sessions have striking parallels to the subjective accounts of people who have had near-death experiences (NDEs) (Ring, 1984). When I had the opportunity to interview people with NDEs, I was immediately aware of a similarity in the emotional tone and experiential quality they conveyed as they talked about what had happened to them. These experiences, including their profound impact on the individual, appeared identical to those of many of my psychedelic psychotherapy patients. The highly charged, subjective value of these experiences was confirmed by their fostering deep positive changes in the person's attitude toward the experience of being alive. In order to convey the human dimensions of the treatment of terminal cancer patients with psychedelic drugs, and in order to illustrate the parallels to NDEs, I would like to share with you a poignant clinical experience. I hope this will foster appreciation and understanding for the humanitarian value I see in the use of psychedelics to aid psychological healing and assist people facing death. This account is a reconstruction and recollection of my own experiences and those of others involved in the process. I hope to convey to you the transcendent realities of psychedelic consciousness. I have shared the unity implied by the mystical dimensions of this psychedelic experience, and therefore fully report my own experiences as a participant-observer in the process.

I look back 15 years so that we can explore together the interwoven meaning these events had for my patient, my co-therapist, and myself as a fledgling researcher and psychotherapist. During this event we confronted death together, and each found a deeper meaning in our lives. Experiences such as this one are the essence of how psychedelic psychotherapy heals.

I came to know my patient, through the process of therapy, as a remarkable person, one who struggled with great courage to experience consciously the final facets in the jewel of his lifetime. This experience had special meaning for both of us because, for each of us in our own way, it was both a first as well as a last experience. For Joe, it was his first and last experience with our research team and with the drug DPT, a psychedelic with a dose-dependent short duration of action. For me, it was my first experience with a terminal cancer patient, 
a joyous surrender of significant aspects of my innocence as a psychedelic psychotherapist and a human being. It is my impression that the entire treatment team, myself, the co-therapist, and Joe, emerged from this event with significant personal growth. This experience has stayed with me over the years as a special memory, one that has become polished by repeated fond recollection.

He was 70 years old. His cancer began in the eye, then spread to his prostate, and ultimately insinuated its way into his other abdominal organs. As the disease progressed, his surgeon noted signs of depression, and a markedly increased need for pain medication. This led the doctor to recommend our experimental treatment with psychedelic drugs. He had seen the treatment help other patients dramatically, so perhaps Joe would improve too. The staff person at the Maryland Psychiatric Research Center, who was in charge of the project, laughed as he told me that I would have fun treating this man because he had lived with his mother for his whole life. My colleague was taking this as an opportunity to chide me. He knew that I had been raised by my mother and only recently married and moved away from home. Although Joe was 70 years old, he still had not married or moved out.

As I walked up to the Cancer Unit, I prepared myself for what I anticipated would be a significant experience in my career as a therapist. I remembered that for me a very important part of my role as a healer was to assist people in experiencing the fears and joys that are the hallmarks of confrontation with the boundaries of human existence. I was resolved to learn everything I could from this experience. At the same time I was quite critical of a modern medicine that emotionally abandons patients near death.

Joe was in a ward with several other patients. I asked the nurse who showed me in where we might go for some privacy. She acted surprised. After walking us out to the hall, she quickly darted in and out of several doors, and then apologetically offered us the janitor's room. There were brooms and pails strewn around the closet-sized office. The nurse left us with the parting wish that we not be disturbed by janitors looking for their tools. My shiny pride in the supposed prestige of my new role was a bit tarnished by the idea of meeting in a broom closet, but there seemed no alternative.

When I asked him about his stay in the hospital, Joe was quite jovial. He chatted offhandedly about the excellent treatment, and told me, perhaps a bit too loudly, of his implicit trust in the doctors. He said that the doctors might have to remove his eye because of the cancer. This was said with such a matter-of-fact and emotionless tone that he could have been describing the cosmetic removal of a wart rather than 
one of the organs vital to sight. When I asked him how he felt about possibly losing his eye, Joe replied without a moment's hesitation that whatever the doctors decided he would accept. He quickly went on to say that there were many more important things for us to discuss. I was expecting him to say something about his impending demise, but to my astonishment he said that I needed to understand labor unions. I decided that although that wasn't my agenda for our meetings, I would have to follow my training and allow Joe to express whatever was on his mind. What began by sounding like a lecture on how to organize a labor union slowly changed into a recollection of the important events in Joe's life. As I started to feel the power and beauty of the life Joe had led, I began to appreciate the privilege of hearing his story.

I learned that Joe was an electrician, and had worked with his hands all of his life. He had retired five years earlier. Joe spoke at length about his life as a working man. When Joe was six, his father was blackballed in the United States. He was prevented from working as a riveter because he was involved in attempts to organize a labor union. So Joe's father, together with a group of friends, had to gather together enough money to get over the border into Canada to find work. To prevent the immigration of vagrants, the Canadian government, at that time, required a $\$ 50$ bond to cross the border. The group could only gather enough funds for one man to cross the border at a time. Once that person found work, the first paycheck was sent back to fund the transfer of another friend into Canada. Joe was outraged that this had been the plight of early union organizers. They were only trying to improve working conditions.

Joe, his brothers, and one sister were raised in a northern state. They struggled to survive on the meager income from his father's Canadian job. When Joe was 11, his father got permission for him to work as a water boy on the riveting gang. This took Joe out of school, but he was glad for the opportunity to help support the family. Joe described his father as a hard working, hard drinking man, who was very kind to his children. He remembered playing ball with him on weekends, and being fascinated by his stories about working and organizing.

Joe described for me the working conditions riveters faced in that era. The men worked in cruelly confining spaces on hot days made hotter by the blazing coal fires used to heat the rivets. When the supervisors were away, Joe's father had allowed him to work as a "holder on." This job meant Joe spent his days using all of his youthful strength to hold a red hot rivet in place, while another worker peened the end of it. He was especially proud of the way he cleaned up the crew's water bucket, which had been rusty and dirty when he arrived. 
At first, he had asked that the company purchase a new water bucket. When they refused, he cleaned up the old one so that the men could drink clean water regardless of company policy.

Joe's mother was the backbone of the family. She was still living, though his father had passed away many years before. Joe said her faculties were undiminished even though she was 90 years old. $\mathrm{He}$ lived with her and his only sister, Jean. Joe said his mother was a warm, comforting, and emotionally available person throughout his childhood. Joe never married. He had a girlfriend when he was in his twenties and, though he proposed marriage to her, she didn't accept because of her family's counsel against marrying a man who drank as much as Joe did. I asked if he really drank that much, and Joe said, "I must admit I could really put it away," quickly adding that all his fellow workers did the same. As a way of explaining this, Joe told me that throughout his childhood the men all worked in gangs, and the foreman of each gang received the weekly pay in gold. So on payday the entire gang of men would adjourn to a tavern immediately after work. At the bar, in the process of dividing up the money, they inevitably drank a fair measure of their income. Joe spoke of alcohol fondly, almost as though he were talking about a person, a working man's friend and entertainer, who gave a few moment's respite from the grueling daily labor that made up the lives of the men. He said he had to give up drinking in 1955 because he had suffered heart damage from an accidental electrical shock at work. Though he was sad to lose the companionship, he apparently had no great difficulties in giving it up.

Joe moved to an eastern seaboard city, where he began his efforts to create a union. He said it all started with a few men meeting in bars after work, dreaming of how things could be. He told me of the fantastic battle with management, of the dirty tactics the company used in trying to scare the men out of a strike, and of his persistence and dedication to the men in the yard. As our meetings became more intimate, he recalled some of his disappointments. He discovered some of the men were stealing from the union's funds. He was especially hurt when one of them turned out to be a trusted friend. Joe said he always tried to handle these incidents with care and secrecy, encouraging the man to pay back his debt and resign.

Joe's attitude during the early interviews was heavily pedantic. Our meetings had the tone of a class on labor relations. He strongly denied any fears of losing his sight, and spoke optimistically about the future. In his talks with me, Joe acted as if his health were fine except for the pain. Joe's surgeon assured me that he had discussed the diagnosis and prognosis with him in detail. Joe was discharged from the hospital. He 
was complaining of constant abdominal pain, and was receiving substantial doses of narcotic medication without great effect.

Our meetings were continued at the Maryland Psychiatric Research Center. We were able to continue our meetings in one of the comfortable drug treatment suites, which was furnished like a living room. Our meetings began to have a more relaxed and less cramped atmosphere. During our second interview at the center, I suggested to Joe that he try listening to some music over stereo headphones while wearing eyeshades so that he could see perhaps a small glimpse of what the psychedelic drug treatment session would be like. I talked to him about how important this experience might be. I advised him to use the drug effects as an opportunity to go within himself. Perhaps he could see if the feelings about his illness and pain were somehow related. Joe, exuding confidence and bravado, allowed me to place the earphones and eyeshades on him. As soon as music was played, his tone became complaining and angry. At first the music was too loud; then he found it reminiscent of riveting. When I asked Joe what riveting reminded him of, he became panic stricken and removed the eyeshades and earphones. He paled visibly and in a frightened voice told me that he was unable to continue and asked if I would please turn off the music. I complied. Joe told me that he had suddenly experienced overwhelming fear at the thought of losing his sight. He said that up to this point he had not realized how frightening this might be. At this juncture, Joe's attitude toward me changed drastically. When he became frightened his authoritarian manner dissolved. He revealed himself as a man genuinely scared of what the future might bring. Over the next few interviews, Joe and I discussed his claim to ignorance of the most likely outcome of this illness. When I suggested to him that he discuss the prognosis with his physician, Joe took refuge in the belief that the doctor would tell him everything he needed to know, "Just as soon as the test results are in."

One day, Joe complained of pain during the beginning of an interview. I asked him if he wished to know what the medical findings were in his case. He said yes, and I informed him of how the cancer had spread throughout his body and that doctors found, in cases where this happened, that the most likely thing-though no one could predict the future with certainty - was death. Joe didn't act surprised or shaken; instead he said he'd secretly suspected for some time that he was dying. He had taken special precautions to shield his mother from any knowledge that he was ill. He said that it was clear to him now this attitude of protection was also his attempt at shielding himself. "If I pretend my cancer doesn't exist for my mother's benefit then I don't have to look at it myself," he said. 
As part of the preparation for Joe's session I interviewed his sister Jean. She lived in Joe's mother's house with him. Jean was quite upset about Joe's illness and ultimate demise, which she considered fait accompli. During a short interview I attempted to communicate to her that it was possible for Joe's last days to be a beautiful time of enhanced closeness and interpersonal warmth for the whole family. Jean seemed somewhat reassured by our talk, but she still seemed more focused on her own anticipatory grief and feelings of abandonment than on relating to her brother as the alive human being that I was coming to appreciate in my interviews. I offered Jean the opportunity for additional therapy sessions; however, it became clear that she did not wish to consider herself as needing help. I made it clear to her that often in times of severe stress such as this, talking with someone about the difficulties could help, and that I would be available to her throughout Joe's illness. In watching Joe and Jean together, it seemed that the attitude of fear and denial on both of their parts was responsible for diminished human contact at a time when warmth and love are the best treatment available. I asked myself what I could possibly do to change this state of affairs. There was no ready answer to my question.

Joe and I discussed his upcoming drug session as a special opportunity for him to review and express the feelings he had inside of himself. Joe was confused as to what I meant by his "insides." He had never imagined that there was a possibility of inner experience until our meetings and hadn't felt that he could change anything about the way he felt about himself or his life situation.

With some trepidation, I scheduled Joe's drug session. It was my feeling that we had established a good rapport over about ten hours of therapy; however, it was still extremely difficult for Joe to introspect and share his emotions. Joe continued to use denial as a way of fending off his fear of death. Although we had been able to break through this barrier sometimes, in his daily life Joe still spoke constantly of the future as though his complete recovery were certain. I experienced great hesitation in telling him that death was almost inevitable. It was my fear that he might take this news as a death sentence. I tried to convey clearly the fact that medical understanding of cancer is incomplete and that recovery could take place though it wasn't likely. We were able to talk about death in the abstract, as something all people must eventually face. I told Joe that coming to terms with our fear of death can lead to enhanced enjoyment of what life remains.

I introduced Joe to my co-therapist for the drug session, Mrs. Nancy Jewell. Nancy was in her early sixties, a psychiatric aide who had been working with the director of the Research Center for years. I liked 
Nancy very much and sometimes would think of her privately as my "West Virginia Mama" when I heard the words of a then-popular song by John Denver. When I brought Nancy and Joe together there was such an immediate rapport that I was amazed, and a bit jealous, that they took to each other so suddenly and completely. After all, I had been building my relationship of trust with Joe gradually and tentatively for several weeks now.

On the day of the drug session Joe arrived in considerable pain. According to my instructions, he had discontinued his pain medication on the day before the session. Nancy and I made him as comfortable as we could on the couch in the treatment suite. At 9 a.m. Nancy administered $90 \mathrm{mg}$ of dipropyltryptamine (DPT) intramuscularly, a dosage capable of producing profound experiences in a willing individual. I placed the eyeshades and earphones on Joe and suggested that he allow the music to carry him through the experience. I also advised Joe to confront whatever experience should present itself. Joe began to complain of pain and I advised him to enter the pain as fully as possible. Joe began to scream, "God damn it! . . This is terrible, I can't stand this any longer!" He asked me repeatedly if he could remove the eyeshades and earphones. I asked him to trust Nancy, myself, and himself by facing the feelings, no matter how terrible they might seem. I encouraged him to yell, scream, and express the powerful emotions in any way he could. Nancy reassured him when he expressed concern that his cussing might offend her.

Over the next 45 minutes Joe thrashed, struggled and experienced difficulty in breathing. We monitored his respiration rate as slightly elevated. The struggle culminated when Joe said, "I guess in the end you just have to give in." This statement was followed by a deep sigh and a profound relaxation of his musculature. He listened to the music peacefully with a contented smile on his face for about 30 minutes.

Joe then called Nancy and me over to the couch. He held our hands. He spoke of being a child, of the difficulties he experienced being poor, of the joys of his profound identification with his father and the struggle that was his father's. Joe said he was experiencing that his father's struggle was also his own and at the same time it was the struggle of all men. The struggle to overcome life's difficulties; the pain, the disillusionment, and the horror of being alive. Joe said, "I feel like I am becoming the blood that flows through my veins. It's Irish blood! There is strength here, I feel the strength of the Irish people. The noble strength of working men. I can feel the meaning of the struggle, of my Irish ancestors. They are stubborn and strong." Joe said he experienced the ideals and dreams that brought his people and others to this 
country as immigrants. "They wanted to overcome pain, injustice and suffering with their strength, not just for themselves but for all of us. I share this struggle. It has been my struggle to carry forward these ideals through my work with the union."

Joe's face softened and looked young. He spoke about his early jobs. He had dropped out of school and worked as a child so that his brothers and sister could have shoes and could attend school. He remembered working, in his teenage years, for the railroad as an apprentice mechanic in the roundhouse. He smiled with foolish pride and overblown confidence, as he boasted of his abilities as a boxer. He showed us the fate of this kind of attitude in his life by narrating his vivid recollection of an encounter he had with a fireman. He told this fireman where to go because the guy had left a locomotive in a mess for Joe to clean up. As they fought, Joe realized that he'd met his match in boxing, but Joe's pride would not allow him to admit defeat even though he was clearly losing the fight. The fireman finally knocked him unconscious. Joe said this was a valuable lesson for him. He learned to have humility about his strength and other virtues. "No matter how big you are, there is always someone bigger and stronger than you willing to knock you in line if you act too big or too proud."

Then Joe looked very sad, and he told us about the girl he had wanted to marry. He looked like he wanted to cry. I encouraged him to use the session as his chance to express all his feelings. I asked him not to hold anything back, to share all of himself with us. Joe said that in his family he had learned a man can do many things, but one thing he should never do is let another man see him cry. I told Joe that crying is part of being human and a person's strength can grow through letting tears express what words cannot. Joe described his feelings of longing for his fiancee. He told us how much he loved his girl and wanted to marry her. I watched as his psychological conflict over crying expressed itself in a physical struggle. Joe was holding his breath and tensing his muscles as though trying to hold back the heavy burden of his feelings. Finally, he surrendered, and deep sobs racked his now frail body.

After crying, Joe went on to describe his role in organizing the labor union in the shipyard, the long hard struggle with management, the difficult working conditions, and how he was moved to action when he saw men suffer. The fullness with which Joe emotionally relived all of this intense life experience, as he shared it with us, was deeply moving. He was able to cry now with less of a struggle, and he expressed, in beautiful, openly flowing tears his compassion for fellow workers' suffering. He fumed and spit his hatred for those managers and fore- 
men more interested in production quotas than in human welfare. The drama and grand sweep of this man's life and his efforts seemed all the more poignant as he shared the depth of his humanity so openly.

There was a broad satisfied smile on Joe's face as he shared his exultation over the inauguration of a new four-million-dollar union hall. He had helped inaugurate the new building a few years before his retirement. As he beheld the costly new building, he contrasted this victory with the experience he had, close to 40 years before, when a local merchant was not willing to accept a check written on the union's first checking account. Joe's expression changed suddenly and he was able to admit for the first time the pain that his mandatory retirement had caused him. He told us how much it meant to be called "Mr. Union" by his friends, and even by his enemies, at work. Joe described the sinking feeling he felt when he was told that because he was now retired, he could no longer prepare union cases for arbitration. $\mathrm{He}$ shared with us the hurt he felt at being excluded from participation purely on the basis of age. He said that if he knew he were going to live long enough, he would take on a struggle for the rights of older people.

Joe's sister and niece arrived to pick him up. Joe was able to sit up comfortably in a chair. I asked him if he was still in pain. In a cheerful manner, and with a smile, he admitted that he "hurt something fierce." Joe was relaxed and joyous, reminiscing with his family about happy events in their childhood. His positive mood was infectious, and soon all present were enjoying the pronounced psychedelic afterglow. I allowed Joe to leave the center at about 3:30 p.m. after making an appointment for the following day.

The next morning, Joe arrived for his appointment promptly, and announced that he was uncertain as to exactly what had taken place the day before. He claimed that his mind was completely blank. I asked whether he felt any relief from his pain. He said that he hadn't. When Joe failed to remember his session, even after I mentioned some of the highlights to him, I became openly disappointed with him. I told him that I could not believe that he had no recall for the moving and profound experience that he had narrated so eloquently the day before. Nancy was also present during this interview, and I experienced her presence as very important; it allowed me to confront Joe more powerfully than I would have dared were I alone with him. I openly challenged his denial, repeating for him his own description of the content of his experience. I bluntly told him that if this was an example of how he expected to deal with death, that I was sure he would find death hard. If he could make use of his drug experience, where he looked death right in the eyes, and could continue to be as courageous as he 
had been, then he would be able to see that his life could still be precious and that death, when it came, could be kind and gentle.

Joe looked somewhat sheepish. He asked that I go a little easy on him. He acknowledged that he could remember what happened the day before. The drug experience was so new and different to him that he found it difficult to understand and accept. Nancy and I reassured him that the experience was genuine, and worked with him by discussing the different aspects of the session. When Joe returned for his next interview, he told me that he had been having a great time being with his family, and that he had started going through his rather large collection of tools. He said that the experience with DPT reminded him that one of the deepest pleasures of being alive is the ability to give pleasure to others. He had gathered together all of his tools and made up three tool boxes. One of these went to his brother, one to his nephew, and the third to the workshop for the blind. Joe said that it was plain to him, through his physical deterioration, that death was near. He told me that death was no longer so frightening. He planned to spend as much time as he could with his family before his time here ended.

This was the last meeting I had with Joe. I tried unsuccessfully to reach him by telephone several times, but was informed that the telephone would not reach his bed. Joe's niece relayed his regards, and said that Joe spoke so warmly of me, she wished she could arrange another meeting for us. I told her that I would be glad to come out to the house and visit Joe. She said Joe's sister was still trying to keep his mother from knowing the grave situation he faced. His mother had recently broken a hip and was bedridden in another part of the house. Therefore, they preferred that I not visit the household.

I was told by the family that Joe died peacefully, without sedation, about two months after his drug session. One of the secretaries at the Research Center saved the obituary for me, and I felt my body tingle and could feel tears welling up in my eyes as I read the headline: "MR. UNION DIES." I knew that Joe would have been really pleased.

\section{Conclusion}

Our own death is a central and frightening mystery of personal existence. The inevitable, nonnegotiable quality of this end is hard to contend with and, therefore, easy to deny in daily life. This is surely part of the reason why the experience with Joe was an especially meaningful one in my training. I gained insight into my own feelings, 
and how they affect my conduct as a therapist. I had my own reasons and goals for helping Joe to confront his fears and emotions concerning death. Yet how could a 22 year-old young man feel that he could have anything to offer his elder facing such an emotional enigma? In order for this experience to be valuable, it needed to be preceded, as it was, by a series of carefully supervised training sessions. I had personally confronted many aspects of my own fears and feelings about death in these sessions. These professional training experiences with psychedelics had provided me the utterly convincing personal experience of confronting death. This gave me the conviction that, although I hadn't physically died, I knew firsthand of some of the emotions that surround such an event. My own experiences, skillfully supported and interpreted by my training therapist, taught me how fear of death feels and manifests itself under the effects of a psychedelic. I also learned in this way, and through less dramatic didactic means, how people respond to the effects of a psychedelic drug in a therapy relationship, and how I might manage the responses helpfully.

The training sessions and my training psychotherapy experiences also involved confronting the fact that I grew up without a father. These factors amplified the emotional impact of this first experience with a dying person. As I accompanied Joe through his treatment process, he offered me something of great value, a deep sharing of his wisdom as an older man reflecting on the meaning of his life. I felt that as the nurturing between father and son that I had missed. This process, then, was mutually rewarding and beneficial. Somehow, my need to listen, understand, and help joined with his need to tell the story of his life to produce an experience of deep meaning and healing for us both.

The basic unity of the shared experiences around the psychedelic session is an outstanding attribute of psychedelic therapy. My own personal history and training, combined with my developing relationship with Joe, his personal history, his relationship with Nancy and her relationship to each of us all blended together to create the set and setting for Joe's experience. It is not really only Joe's experience, or my experience, or Nancy's experience, but rather the beautiful confluence of meaning in this session that was so moving and significant for each of us. Joe's experience was not only psychedelic for Joe, but also for me, and for Nancy too, even though we were not under the pharmacologic influence of any drug. In the process of this kind of clinical research one is forced to reduce many experiences, like these, to a set of before and after measurements to be reported to the scientific community. I feel that much meaningful, and perhaps even the most relevant and 
important, information is lost in that way of communicating about this work. We do not yet know, or fully understand, all the elements that influence the process and therapeutic outcome of experiences with psychedelics. There is no valid way to separate subject from object or therapist from patient in these studies, even though our scientific methods force us in this direction. We are, in these situations, treating the human condition with which we are all cursed and blessed. I present this work here with the hope that sharing such experiences might help to overcome the fear and misunderstanding so prevalent in our society's repressive reaction to this work. When properly used, psychedelic drugs, and the vast frontier they open, can help us in our struggle to understand, to accept, and on occasion to transcend, the limitations of our own humanity.

\section{References}

Kurland, A. (1985). LSD in the supportive care of the terminally ill cancer patient. Journal of Psychoactive Drugs, 17, 279-290.

Richards, W., Rhead, J., Di Leo, F., Yensen, R., \& Kurland, A. (1977). The peak experience variable in DPT-assisted psychotherapy. Journal of Psychedelic Drugs, 9, 1-10.

Ring, K. (1984). Heading Toward Omega. In Search of the Meaning of the Near-Death Experience. New York, NY: William Morrow. 